\title{
Abrupt Transitions in Submesoscale Structure in Southern Drake Passage: Glider Observations and Model Results
}

\author{
Giuliana A. Viglione, Andrew F. Thompson, And M. Mar Flexas \\ California Institute of Technology, Pasadena, California
}

JANET SPRINTALL

Scripps Institution of Oceanography, La Jolla, California

SEBASTIAAN SWART

University of Gothenburg, Gothenburg, Sweden, and University of Cape Town, Cape Town, South Africa

(Manuscript received 19 September 2017, in final form 25 April 2018)

\begin{abstract}
Enhanced vertical velocities associated with submesoscale motions may rapidly modify mixed layer depths and increase exchange between the mixed layer and the ocean interior. These dynamics are of particular importance in the Southern Ocean, where the ventilation of many density classes occurs. Here we present results from an observational field program in southern Drake Passage, a region preconditioned for submesoscale instability owing to its strong mesoscale eddy field, persistent fronts, strong down-front winds, and weak vertical stratification. Two gliders sampled from December 2014 through March 2015 upstream and downstream of the Shackleton Fracture Zone (SFZ). The acquired time series of mixed layer depths and buoyancy gradients enabled calculations of potential vorticity and classifications of submesoscale instabilities. The regions flanking the SFZ displayed remarkably different characteristics despite similar surface forcing. Mixed layer depths were nearly twice as deep, and horizontal buoyancy gradients were larger downstream of the SFZ. Upstream of the SFZ, submesoscale variability was confined to the edges of topographically steered fronts, whereas downstream these motions were more broadly distributed. Comparisons to a one-dimensional (1D) mixing model demonstrate the role of submesoscale instabilities in generating mixed layer variance. Numerical output from a submesoscale-resolving simulation indicates that submesoscale instabilities are crucial for correctly reproducing upper-ocean stratification. These results show that bathymetry can play a key role in generating dynamically distinct submesoscale characteristics over short spatial scales and that submesoscale motions can be locally active during summer months.
\end{abstract}

\section{Introduction}

The Southern Ocean plays a key role in Earth's climate owing to the ventilation of deep waters and the subduction of newly formed intermediate and bottom waters. Upwelling and subduction rates depend on surface forcing, mixed layer depths (MLDs), and the spatial and temporal distribution of surface outcrop positions of density classes (Marshall 1997; Abernathey et al. 2016). Oceanic submesoscale motions are known to significantly impact upper-ocean stratification and exchange between the mixed layer and thermocline (Klein and

\footnotetext{
Corresponding author: Giuliana A. Viglione, giuliana@caltech. edu
}

Lapeyre 2009; McWilliams 2016). The submesoscale is distinguished by Richardson (Ri) and Rossby (Ro) numbers approaching $O(1)$. Unlike low-Ro, large-scale flows, which drive horizontal stirring of large-scale buoyancy and tracer gradients, submesoscale motions lead to large vertical velocities and fluxes (Mahadevan and Tandon 2006).

The Southern Ocean and the Antarctic Circumpolar Current (ACC) are associated with many of the characteristics that are conducive to generating submesoscale motions: (i) persistent frontal currents with strong lateral buoyancy gradients, (ii) strong surface forcing, (iii) vigorous stirring by an energetic mesoscale eddy field, and (iv) weak vertical stratification. While much of our understanding about submesoscales has been achieved 
through idealized modeling approaches (e.g., Boccaletti et al. 2007; Capet et al. 2008; Thomas and Ferrari 2008; Mahadevan et al.2010), regional, submesoscale-resolving simulations in the Southern Ocean, such as around Kerguelen Plateau (Rosso et al. 2014) and Drake Passage (Bachman et al. 2017b), have demonstrated the impact of these scales on upper-ocean stratification and vertical exchange with the ocean interior. In particular, Rosso et al. (2014) reports enhanced vertical exchange and velocities when submesoscales are resolved, while Bachman et al. (2017b) shows that mixed layers shoal with increased model resolution.

Observations of the submesoscale in the Southern Ocean are sparse because of the difficulty and expense of field campaigns in this region. Even in Drake Passage, which is the most intensively studied region of the Southern Ocean (Meredith et al. 2011), observations are typically carried out on large temporal and spatial scales, such as the repeat expendable bathythermograph sections of Drake Passage (Sprintall 2003) and the U.K.-led SR1b line. Little observational work is available at the submesoscale to corroborate the modeling work that has been done in the region. Adams et al. (2017) provides a notable exception; this field program surveyed an active submesoscale field surrounding a large coherent mesoscale eddy pinched off from the Polar Front. New analysis of high-resolution model output by $\mathrm{Su}$ et al. (2018) suggests that the Southern Ocean also has the smallest seasonal cycle of submesoscale activity. In contrast to in situ studies in subtropical regions, which predominantly found submesoscale activity in wintertime (e.g., Callies et al. 2015; Thompson et al. 2016; Hosegood et al. 2013), we present evidence for intermittent episodes of a highly active submesoscale field during summer months in southern Drake Passage.

In recent years, autonomous underwater vehicles, such as Seagliders, have been increasingly used as a method of observing submesoscale dynamics over longer time periods than is allowed by ship-based field campaigns. A 2008 observational study in the North Atlantic used gliders to provide evidence for an eddydriven restratification of the upper ocean that spurred spring phytoplankton blooms in the North Atlantic (Mahadevan et al. 2012). More recently, the 2012-13 Ocean Surface Mixing, Ocean Submesoscale Interaction Study (OSMOSIS) campaign studied a small patch of the open ocean for an entire year, documenting a range of submesoscale instabilities (Thompson et al. 2016). Todd et al. (2016) used gliders to study the potential vorticity (PV) structure of the North American western boundary currents, and du Plessis et al. (2017) carried out similar analyses in the ACC's subantarctic zone.
The goals of the field program presented here, Changes in Stratification at the Antarctic Peninsula (ChinStrAP), were to observe mixed layer depth variability and its impact on the ventilation and subduction of near-surface water masses at submesoscale temporal and spatial resolution. ChinStrAP provides the first submesoscale-resolving seasonal-scale observational experiment in Drake Passage, collected by Seagliders over a period of 4 months in the austral summer of 2014/15. The gliders sampled on either side of the Shackleton Fracture Zone (SFZ), providing insight into two distinct dynamical regimes. Upstream of the SFZ, the southern boundary of the ACC (SBACC) and the Southern ACC Front (SACCF) are strongly constrained by topography close to the shelf, but deflect northward as they pass over the SFZ (Orsi et al. 1995). The injection of Weddell Sea Waters by the Antarctic Slope Front (ASF) (Gill 1973; Jacobs 1991) and Weddell Front downstream of the SFZ (Heywood et al. 2004; Thompson et al. 2009) lead to further differences in properties between the regions (Patterson and Sievers 1980; Whitworth et al. 1994). Although we cover a relatively small region of the Southern Ocean, these observations show abrupt changes in the characteristics of the submesocale motions and their impact on the upper-ocean hydrography; lessons from this region may be extended to other parts of the Southern Ocean.

Following earlier observational studies, we analyze the glider data for instances where the ocean is preconditioned toward gravitational and/or symmetric instability in the mixed layer. Symmetric instability is a shear instability that extracts kinetic energy from geostrophic flows via slantwise convection. The resulting rearrangement of water parcels leads to low PV in the mixed layer, conditioning it to further submesoscale instabilities (Haine and Marshall 1998). We also investigate the relative impacts of mixed layer baroclinic instability (BCI), which shoals the mixed layer by the slumping of isopycnals (Haine and Marshall 1998), and Ekman buoyancy flux (EBF), or wind-driven re- and destratification (Thomas 2005). When a wind stress is applied in a down-front orientation, the resulting Ekman transport carries denser water over lighter waters, causing vertical convection and a destruction of stratification and PV. When the wind has an up-front orientation, the Ekman transport moves lighter water over denser water, causing an increase in stratification throughout the Ekman layer depth, which can lead to a restratification of the mixed layer. Parameterizations are used to compare the potential effects of Ekman buoyancy flux and BCI on the mixed layer buoyancy budget. As in du Plessis et al. (2017), we use a onedimensional (1D) mixed layer model to discern the role 

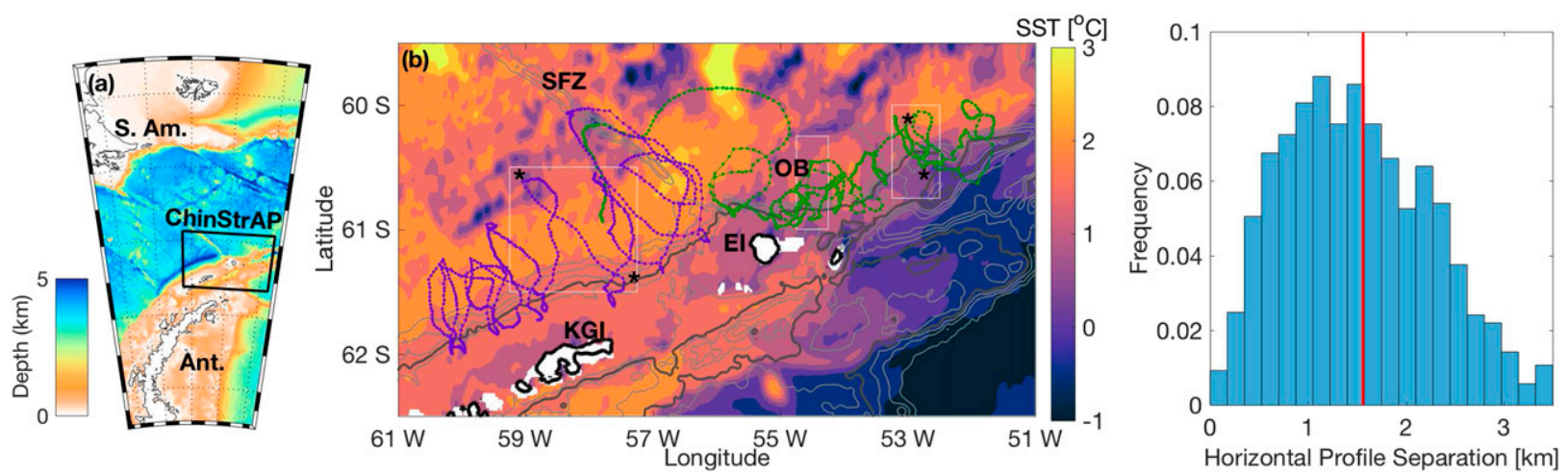

FIG. 1. Overview of the ChinStrAP field program. (a) Bathymetry of Drake Passage region (from ETOPO1) including the ChinStrAP study area (black box). (b) ChinStrAP glider lines from SG-W (purple) and SG-E (green) are overlaid on 1-km-resolution GHRSST from $3 \mathrm{Feb} 2015$ (Chao et al. 2009). Bathymetric contours are shown in 500-m intervals (gray) with the 0-m contour in black and a thicker contour for $1000 \mathrm{~m}$. Major bathymetry features are labeled: SFZ, OB, EI, and KGI. Black asterisks indicate sections used in Fig. 3, and white boxes indicate subdomains of LLC model. (c) Histogram of horizontal separation of glider profiles for both vehicles shows a mean of $1.6 \mathrm{~km}$ (red).

of surface forcing on setting upper-ocean stratification. The model is then modified to incorporate the effects of Ekman buoyancy flux and BCI. Our results suggest that these processes are at least as important as the surface wind and buoyancy forcing in setting mixed layer variability in the Southern Ocean. Finally, a high-resolution global circulation model is used to validate our mixed layer observations and to confirm the feasibility of calculating PV from gliders.

The paper is organized as follows. Section 2 contains a description of the ChinStrAP field program, a description of the supplementary datasets used, the theoretical framework used to quantify the effects of submesoscale processes on the stratification of the upper ocean, and a brief description of the bulk mixed layer model used to replicate the observed mixed layers. Section 3 provides a characterization of the study site using previously derived parameterizations to examine the spatial and temporal variability of submesoscale instabilities and evaluates the efficacy of the mixed layer model. Section 4 further analyzes the variability across the SFZ, a prominent bathymetric feature off the tip of the Antarctic Peninsula, and proposes the cause of the dynamical differences between the regions just upstream and downstream of the SFZ. Here we also discuss the limitations of the study. Our conclusions are presented in section 5.

\section{Methods}

\section{a. Field program description}

Two key focuses of the ChinStrAP field campaign were (i) identifying regions of southern Drake Passage that may be conditioned for submesoscale instabilities and (ii) determining the relative importance of submesoscale motions and atmospheric forcing on the upper-ocean stratification. Two Seagliders were deployed north of the Antarctic Peninsula and piloted in cross-shelf sections over a period of four months (December 2014-April 2015) (Figs. 1a,b). Shipboard Rosette CTD casts conducted during the glider deployment cruise were used for glider sensor calibration and initialization of the Price-WellerPinkel (PWP) model [section 3d; Fig. 8a (shown below)].

The gliders profile in a $\mathrm{V}$-shaped pattern, sampling continuous, inclined profiles to either $1000 \mathrm{~m}$ or the ocean floor, whichever depth was shallower. A fulldepth dive took approximately $5 \mathrm{~h}$ to complete and spanned a horizontal displacement of between 0.1 and $7 \mathrm{~km}$, depending on the strength of the background flow (Fig. 1c). A full transect across the shelf was completed over a period of roughly one week. During each dive, measurements of temperature $T$, pressure, and salinity $S$ data were collected from a Seabird SBE3 temperature sensor and an SBE4 conductivity sensor (CTSail). The unpumped CTD sampled every $5 \mathrm{~s}$ throughout the dive, approximately every $1 \mathrm{~m}$. The initial accuracy of the temperature and salinity is approximately $0.002^{\circ} \mathrm{C}$ and 0.002 psu, respectively, with expected drifts over the deployment of less than $0.001^{\circ} \mathrm{C}$ and $0.001 \mathrm{psu}$. Both gliders were additionally equipped with an Aanderaa 4330F oxygen optode, and a WET Laboratories Environmental Characterization Optics (ECO) Puck measuring fluorescence and optical backscatter; an analysis of subduction pathways based on the optical data is given in Erickson et al. (2016).

The raw glider data were processed using the University of East Anglia's Seaglider Toolbox, which corrects for lag and inertial effects, and then were manually 

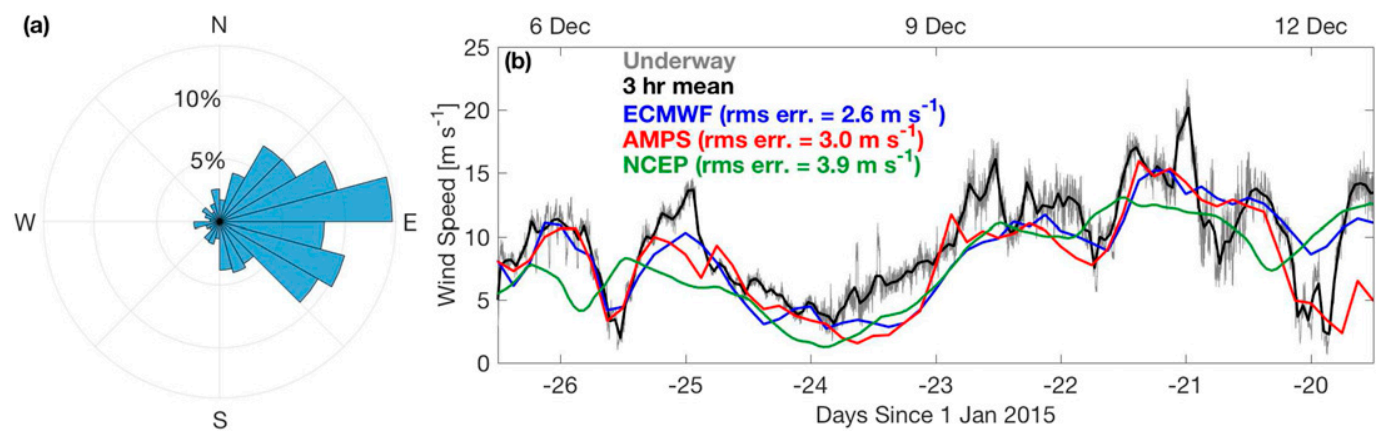

FIG. 2. (a) A histogram of wind directions from ERA-Interim over the study region from December 2014 to April 2015 shows predominantly westerly winds. (b) A comparison of three tested reanalysis products, ERA-Interim (ECMWF; blue), AMPS (red), and NCEP (green), and shipboard wind speed data (instantaneous wind speed in gray, 3-h running mean in black).

despiked. These data were objectively mapped onto a regular grid in depth and time, with a vertical resolution of $5 \mathrm{~m}$ and a horizontal temporal resolution of approximately $1 \mathrm{~h}$ (using a Gaussian weighting function with a vertical scale of $15 \mathrm{~m}$ and a temporal scale of $4 \mathrm{~h}$ ). A comparison of the raw data to the objectively mapped dataset revealed no significant aliasing due to this choice of resolution; a sensitivity study on the horizontal grid showed this resolution to introduce minimal spurious features while retaining the most information about submesoscale processes. The horizontal glider position was interpolated to this grid to give a monotonically increasing along-track distance, from which horizontal spatial gradients could be calculated. This dataset necessarily conflates spatial and temporal variability, and it remains a significant challenge to separate out these effects in our analysis; we appeal to a high-resolution numerical model to provide additional confidence in our analysis.

Glider SG-W was deployed north of King George Island (KGI) at $58.82^{\circ} \mathrm{W}, 61.73^{\circ} \mathrm{S}$, and completed 771 dives over a four-month period. The second glider, SG-E, was deployed northeast of Elephant Island (EI) at $52.48^{\circ} \mathrm{W}, 60.48^{\circ} \mathrm{S}$, and completed 642 dives over three months. The two locations are separated by the SFZ, a large bathymetric ridge that runs northwest-southeast perpendicular to the mean flow of the ACC through Drake Passage (Fig. 1). Throughout the deployment, SG-W predominantly sampled the region upstream of the SFZ, while SG-E remained mainly downstream of the SFZ. Both regions, occupying the same latitudes, experience roughly the same surface heat and surface wind stress. The winds are predominantly westerly and do not vary significantly over the area the gliders sampled. This work considers the influence of submesoscale instabilities on the mixed layer depth and surface buoyancy budget. The mixed layer depth was calculated using a density $(\sigma)$ threshold criterion using
$\Delta \sigma=0.125 \mathrm{~kg} \mathrm{~m}^{-3}$ (Monterey and Levitus 1997); this value was chosen because it gave the best visual agreement with the surface mixed layer in individual profiles.

\section{b. Additional datasets}

Wind speed and wind direction data were available four times daily from ERA-Interim (Dee et al. 2011), which has a horizontal resolution of $\sim 80 \mathrm{~km}$. ERAInterim was selected because it most accurately reproduced both wind speed and direction as measured by the shipboard instruments over a one-week period during the deployment cruise (Fig. 2b). Freshwater and surface heat fluxes were also taken from ERA-Interim to be consistent with the wind stress data.

\section{c. Mixed layer model description}

In the following dataset we explore the impact of lateral (or three dimensional) submesoscale dynamics on setting the upper-ocean stratification. This was achieved by first using the one-dimensional PWP bulk mixed layer model proposed by Price et al. (1986); a similar analysis was carried out by du Plessis et al. (2017) for a different region of the Southern Ocean. Precipitation, longwave radiation, and sensible and latent heat are applied at the surface, while shortwave radiation is absorbed at depth with two wavelengthdependent exponentially decaying terms, with these attenuation distances defined by Paulson and Simpson (1977). Turbulent mixing is parameterized based on the strength of the local wind stress. The surface fluxes and wind stress were interpolated to the glider position at each time step. Using a time step of $1 \mathrm{~h}$, surface buoyancy and momentum fluxes are applied and mixed down through the water column, and bulk and gradient Richardson numbers are calculated. If these are below critical values $\left[\mathrm{Ri}_{b}<0.65 ; \mathrm{Ri}_{g}<0.25\right.$ as in 
Price et al. (1986)], water is entrained from below and the process is repeated.

The PWP model was initialized with the shipboard CTD calibration cast, as the higher vertical resolution acquired by the CTD ( $1 \mathrm{~m}$ as opposed to $5 \mathrm{~m}$ from the glider) was found to improve the performance of the model; there was little difference between glider and CTD profiles at this location. To distinguish the effects of atmospheric forcing from those of submesoscales, advection, and other three-dimensional processes, a modified PWP model (mPWP) was also run, which included parameterizations of an equivalent heat flux from baroclinic instability and Ekman buoyancy flux, detailed in section 2e. The implementation of the mPWP will be discussed further in section $3 \mathrm{~d}$.

\section{d. Potential vorticity calculations}

We follow the framework of earlier studies (Thomas et al. 2013; Thompson et al. 2016; du Plessis et al. 2017) that have used the Ertel PV as a diagnostic tool to determine times when portions of the mixed layer may be preconditioned toward instabilities that will act to restore PV to neutral stability conditions. A brief summary of this technique is provided here. The full Ertel PV is given by

$q_{\text {Ertel }}=\omega_{a} \cdot \nabla b=(f+\zeta) N^{2}+\left(w_{y}-v_{z}\right) b_{x}+\left(u_{z}-w_{x}\right) b_{y}$,

where $\omega_{a}=2 \Omega+\nabla \times \mathbf{u}$ is the absolute vorticity, $f$ is the Coriolis parameter, $b$ is the buoyancy, defined as $b=$ $g\left(1-\rho / \rho_{0}\right)$, where $g$ is the gravitational acceleration, $\rho$ is the fluid density, $\rho_{0}$ is the reference density $1027.15 \mathrm{~kg} \mathrm{~m}^{-3}$ (the mean density over the deployment), $\Omega$ is the angular velocity of the Earth, $\mathbf{u}$ is the three-dimensional fluid velocity, $N^{2}=b_{z}$ is the vertical stratification, and $\zeta=v_{x}-u_{y}$ is the vertical relative vorticity. Subscripts above indicate partial differentiation.

A limitation of the PV approach is that observations are restricted to the vertical and a single horizontal dimension (Shcherbina et al. 2013; Thompson et al. 2016). During this particular mission, the gliders were piloted perpendicular to the fronts to the degree possible based on the current speeds; this limits the error in the twodimensional PV calculation (see section 4). A comprehensive explanation behind the simplifying assumptions made can be found in Thompson et al. (2016), among others. The resulting observational $\mathrm{PV}$ is given as

$q_{\mathrm{Obs}}=\left(-v_{z}, 0, f+v_{x}\right) \cdot\left(b_{x}, 0, b_{z}\right)=(f+\zeta) N^{2}-\frac{b_{x}^{2}}{f}$,

and the validity of these assumptions will be discussed in section 4 .
From the PV calculations, conditions favorable for submesoscale instabilities can be identified using the balanced Richardson number, as in Thomas et al. (2013):

$$
\phi_{\mathrm{Ri}_{b}}=\tan ^{-1}\left(-\mathrm{Ri}_{b}^{-1}\right),
$$

with a critical balanced Richardson angle, $\phi_{c}=\tan ^{-1}(-\zeta / f)$, separating regimes of symmetric, gravitational, and mixed symmetric/gravitational instability from the stable regime.

\section{e. Submesoscale instability calculations}

In addition to the instability criteria described above, which require $\mathrm{PV}>0$ (opposite sign of $f$ ), the release of available potential energy stored in the mixed layer through $\mathrm{BCI}$, which does not require $\mathrm{PV}>0$, may also impact the upper-ocean stratification (Boccaletti et al. 2007). Fox-Kemper et al. (2008) provided a parameterization for the effective streamfunction caused by this baroclinic instability dependent on the mixed layer depth $H$ and horizontal buoyancy gradient $|\nabla b|$. As the gliders can only resolve one horizontal direction, we can write the parameterization as

$$
\psi_{\mathrm{BCI}}=C_{0} \frac{b_{x} H^{2}}{f} \mu(z)
$$

with $b_{x}$ being the horizontal buoyancy gradient in the direction along the glider track. The empirical constant $C_{0}$ may vary throughout the ocean, but in the absence of any direct measurements of this value, we take $C_{0}=0.06$ as in Fox-Kemper et al. (2008) and previous glider studies. The function $\mu(z)$ describes the vertical structure of $\psi_{\mathrm{BCI}}$; here we set this term equal to unity for simplicity. Using $\psi_{\mathrm{BCI}}$ and the lateral buoyancy gradient, the restratifying buoyancy flux can be determined, and for ease of comparison to the surface fluxes, as in Mahadevan et al. (2012), this can be expressed as an equivalent heat flux $\left(\mathrm{W} \mathrm{m}^{-2}\right)$ :

$$
Q_{\mathrm{BCI}}=0.06 \frac{b_{x}^{2} H^{2}}{f} \frac{C_{p} \rho_{0}}{\alpha g},
$$

where $C_{p}$ is the specific heat of seawater and $\alpha$ is the thermal expansion coefficient, a function of temperature and pressure.

Another key factor in setting the stratification of the upper ocean is the interaction between surface wind forcing and upper-ocean fronts, a process known as the Ekman buoyancy flux (Thomas 2005). This effect can also be written as an overturning streamfunction, again with the simplification that we only consider the wind stress component perpendicular to the glider path $\tau^{y}$ : 


$$
\psi_{\mathrm{EBF}}=\frac{\tau^{y}}{\rho_{0} f}
$$

If we again consider the buoyancy gradient in the alongtrack direction $b_{x}$, we can write an equivalent heat flux expression analogous to (5):

$$
Q_{\mathrm{EBF}}=-\frac{b_{x} \tau^{y}}{f} \frac{C_{p}}{\alpha g} .
$$

We acknowledge that our analysis disregards much of the intricacy of the vertical structure of the upper ocean, in particular by eliminating the depth dependence of the $Q_{\mathrm{BCI}}$ parameterization in (5) and by assuming the equivalence of the Ekman layer and mixed layer depths. Nonetheless, observational evidence from Lenn and Chereskin (2009) supports the notion that in Drake Passage, Ekman layer depths approach the annual-mean mixed layer depths of $120 \mathrm{~m}$. Disentanglement of the vertical structure is beyond the scope of the paper, and we will focus on the parameterizations in terms of relative, rather than absolute, changes.

\section{f. Global circulation model description}

Output from a global high-resolution general circulation model based on a latitude/longitude/polar-cap (hereinafter LLC) configuration of the MIT general circulation model (MITgcm; Marshall et al. 1997; Hill et al. 2007) is used to assess the validity of our glider PV analysis. The LLC simulation is a $1 / 48^{\circ} \mathrm{MITgcm}$ model with 90 vertical levels, with a horizontal resolution of approximately $0.75 \mathrm{~km}$ in the polar regions and a vertical resolution of $1 \mathrm{~m}$ near the surface to better resolve the diurnal cycle.

The model configuration includes a flux-limited, seventh-order, monotonicity-preserving advection scheme (Daru and Tenaud 2004) and the modified Leith scheme of Fox-Kemper and Menemenlis (2008) for horizontal viscosity. Vertical viscosity and diffusivity are parameterized according to the K-profile parameterization (KPP) (Large et al. 1994). Bottom drag is quadratic (drag coefficient $C_{D}=2.1 \times 10^{-3}$ ) and side drag is free slip. Partial cells (Adcroft et al. 1997) are used to represent the sloping sea floor in our $z$-level vertical discretization. Bathymetry is from Global Topography, version 14.1, updated from Smith and Sandwell (1997).

The simulation is initialized from a data-constrained global ocean and sea ice solution provided by the Estimating the Circulation and Climate of the Ocean, Phase II (ECCO2), project (Menemenlis et al. 2005, 2008; Losch et al. 2010) and includes tidal forcing. The inclusion of tides allows one to successfully reproduce shelf-slope dynamics and water-mass modification (Flexas et al. 2015). Surface boundary conditions are 6-hourly output from the ECMWF atmospheric operational model analysis, starting in 2011, with spatial resolution of about $79 \mathrm{~km}$. One year of hourly model output of full three-dimensional model prognostic variables is available (from September 2011 to August 2012).

We used three subdomains: one located upstream of the SFZ, one located between the SFZ and the Ona Basin (OB), and one located downstream of both the SFZ and the Ona Basin, plotted in Fig. 1b. Comparisons between the observations and the LLC model were made in order to validate the assumptions made in our calculations of PV and MLD. Temperature, salinity, and horizontal velocities from the model were used to calculate both the Ertel PV [(1)] and an observational PV [(2)].

\section{Results}

\section{a. Site characterization}

The observations collected in the ChinStrAP field program allow for the examination of both temporal (summer and into early fall) and spatial variability of mixed layer depths and dynamics. Following Whitworth et al. (1998), we define Circumpolar Deep Water $(\mathrm{CDW})$ as the subsurface temperature maximum $\theta_{\max }$. In our region, $\theta_{\max }$ corresponds to a neutral density $\gamma^{n}$ of $28.00 \mathrm{~kg} \mathrm{~m}^{-3}$. Water above CDW is Antarctic Surface Water (AASW), and subsurface $\theta_{\min }$ indicate presence of Winter Water (WW) formed during the cold season.

Upstream of the SFZ, the mixed layer depth does not vary significantly, and it is clearly defined by the shallow, warm/fresh AASW that sits above WW (Fig. 3a). Downstream of the SFZ, the mixed layers are much more variable, and there are sharp lateral gradients in the density field that are not associated with the main fronts of the ACC. This is indicative of enhanced stirring by an active mesoscale eddy field (Fig. 3b). In both representative sections, warmer surface waters are found offshore than on the shelf; this pattern is also reflected in the high-resolution SST data shown in Fig. 1b.

The predominant water mass upstream of the SFZ is $\mathrm{CDW}$, which is found all the way up to the shelf break. It is capped by a layer of AASW on top of WW, which leads to the stability in the mixed layer described above. Downstream of the SFZ, there is weak vertical stratification, but there are sharp distinctions between the subsurface water masses in the horizontal as evidenced by the gaps in the $T / S$ structure that are not evident upstream (Figs. 3c,d).

One of the strongest distinctions between the two regions is the depth and variability of the mixed layers upstream and downstream of the SFZ. The mixed layer 

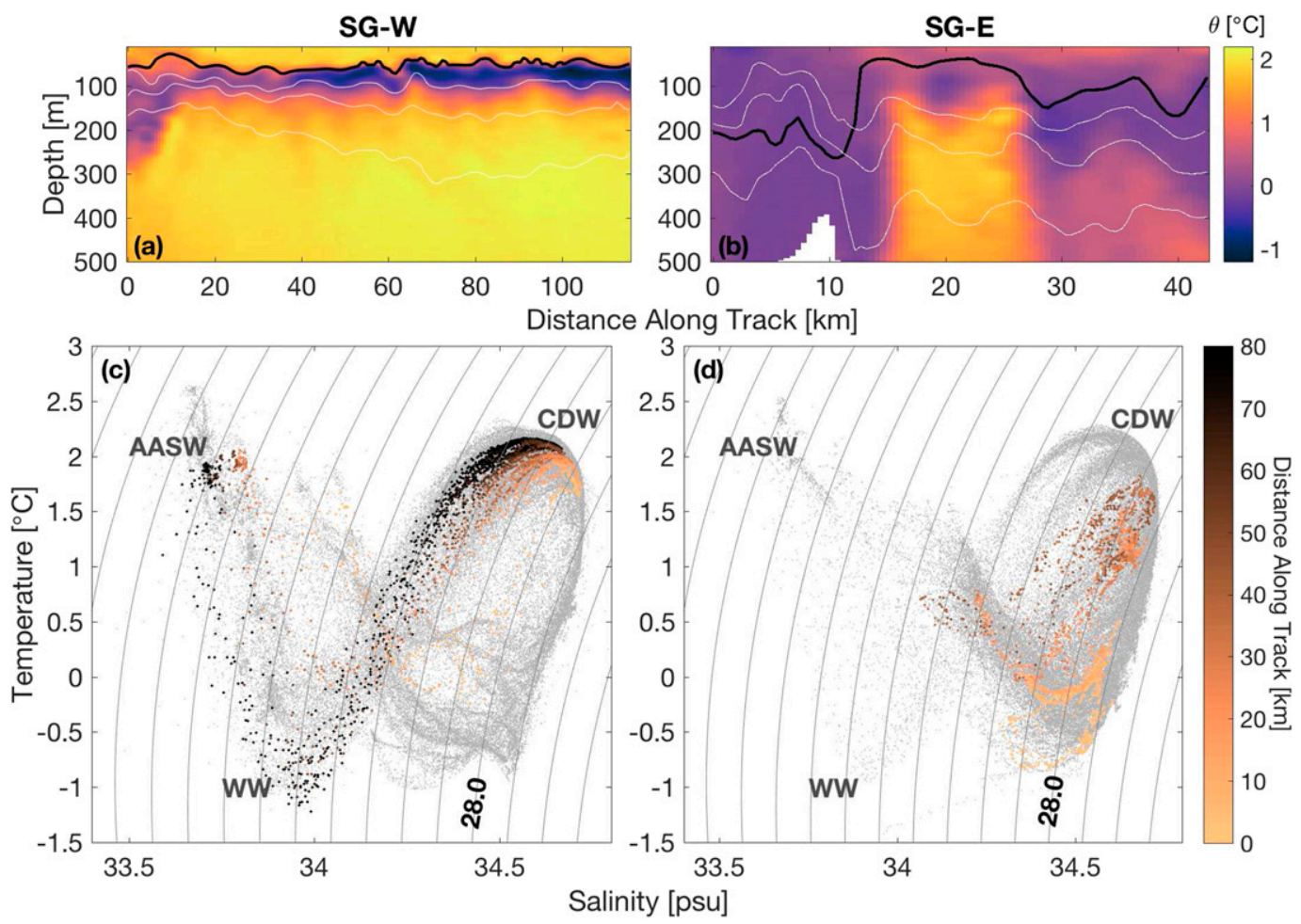

FIG. 3. Temperature-depth sections of glider data (a) upstream and (b) downstream of the SFZ. The sections are denoted by stars on the map in Fig. 1b. The black line is mixed layer depth using $\Delta \sigma=0.125 \mathrm{~kg} \mathrm{~m}^{-3}$, and white contours are potential density surfaces: $27.4,27.5$, and $27.6 \mathrm{~kg} \mathrm{~m}^{-3}$ in (a) and 27.65, 27.7, and $27.75 \mathrm{~kg} \mathrm{~m}^{-3}$ in (b). Temperature-salinity diagrams of glider data collected during the deployment for (c) SG-W and (d) SG-E. Labels denote AASW, WW, and CDW. Contours give neutral density surfaces in increments of $0.1 \mathrm{~kg} \mathrm{~m}^{-3}$, with the $28.0 \mathrm{~kg} \mathrm{~m}^{-3}$ neutral density contour labeled. The gray dots indicate measurements over the entire deployment; the colored dots (enlarged for contrast) give the measurements from the sections in (a) and (b).

depths upstream of the SFZ are $65 \pm 19 \mathrm{~m}$, while downstream the average depth is $119 \pm 92 \mathrm{~m}$. Furthermore, upstream of the SFZ, mixed layer depth has an inverse correlation with bathymetry, with deeper mixed layers being found on the continental shelf/slope and shallower mixed layers as the glider moves into deeper waters (Fig. 4a). In contrast, mixed layers downstream of the SFZ show more spatial variability, with a general trend of increasing mixed layer depth from west to east downstream of the SFZ. SG-E occupied these stations farther downstream from the SFZ at the beginning of the deployment. Since mixed layers would be expected to be deeper in autumn, toward the end of the deployment (Fig. 4b), we attribute this pattern to spatial, rather than temporal, variability. While the peak in the histogram of the mixed layer depths is similar in both regions, there is a much longer tail in the mixed layer depth distribution in the region downstream of the SFZ as compared to the upstream region (Fig. 5a). The glider sampled very deep mixed layers on the shelf downstream of the SFZ, where stratification is low. Previous works (e.g., Patterson and Sievers 1980) have shown that deep mixed layers in this region are not restricted to wintertime, as lateral mixing processes may lead to homogeneity through the entire water column. However, even discarding the data collected over the shelf, the mixed layers downstream of the SFZ are significantly deeper than those upstream.

\section{b. Mesoscale context}

The deflection of the SACCF over the SFZ leads to a more unstable front downstream of the SFZ than upstream, where the front follows bathymetry, essentially being steered by contours of $f / h$, where $h$ is the height of the water column. Similarly, the SBACC, which is also topographically steered upstream of the SFZ, is deflected around the Ona Basin just downstream of the SFZ (Orsi et al. 1995), which may impart additional variability (Barré et al. 2008). The area to the east of the SFZ and surrounding Elephant Island, known as the Weddell-Scotia Confluence, is also prone to increased variability due to the interaction of a number of distinct boundary currents. In addition to the SBACC, the ASF sheds eddies and filaments off Ona Ridge 

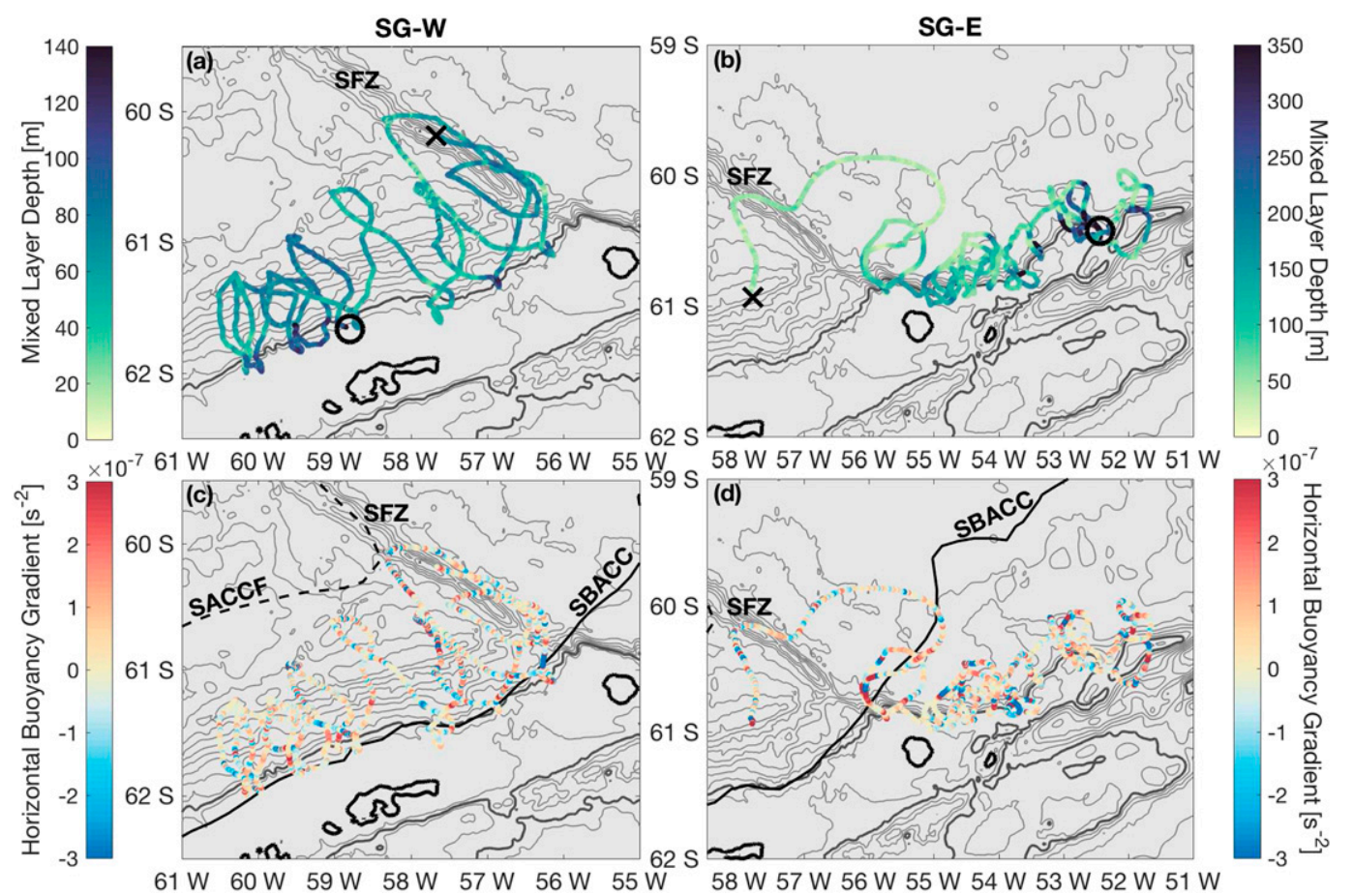

FIG. 4. Maps of (a),(b) mixed layer depths and (c),(d) horizontal buoyancy gradients $b_{x}$ for gliders (left) SG-W and (right) SG-E. The 1000-m isobath is dark; note the difference in mixed layer depth range in (a) and (b). The circle indicates deployment location, and the $\mathrm{X}$ indicates recovery location. The solid black line in (c) and (d) denotes the mean position of the SBACC over the study period, and the dashed line indicates the mean position of the SACCF.

(Flexas et al. 2015), and the Antarctic Coastal Current circulates between the Antarctic Peninsula and the northern islands before meeting up with the ASF (Palmer et al. 2012). The injection of Weddell Sea waters and the shedding of Weddell eddies downstream of the SFZ also results in a region that, while close in distance to the upstream region, is much more energetic (Palmer et al. 2012; Thompson and Youngs 2013).
The horizontal buoyancy gradients exhibit significant variability upstream and downstream of the SFZ. The horizontal buoyancy gradient was calculated as the average over the mixed layer depth, discarding the top $5 \mathrm{~m}$. Upstream of the SFZ, the largest values of $b_{x}$ are located near the positions of the SBACC. Downstream, the high values of $b_{x}$ are not constrained to the mean frontal positions and are indicative of a more energetic
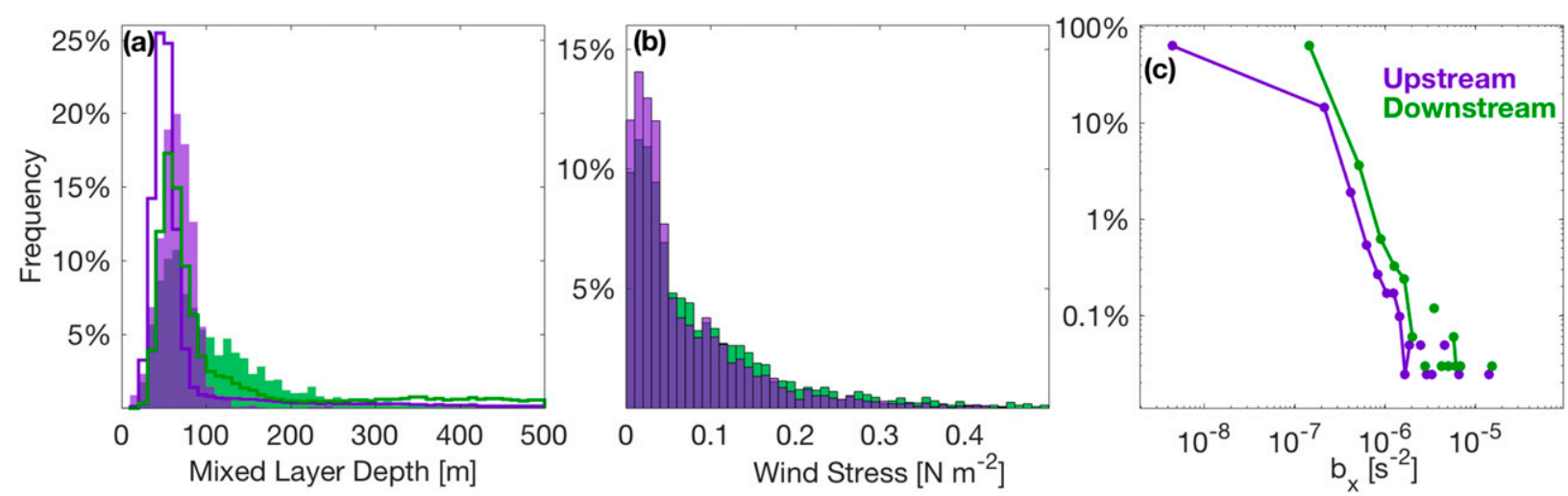

FIG. 5. Comparisons of histograms of key properties upstream (purple) and downstream (green) of the SFZ: (a) mixed layer depth (m), (b) down-front wind stress $\tau^{y}\left(\mathrm{~N} \mathrm{~m}^{-2}\right)$, and (c) absolute value of horizontal buoyancy gradient $b_{x}\left(\mathrm{~s}^{-2}\right)$. In (a), outlines denote MLD from LLC model, boxes from glider observations. 

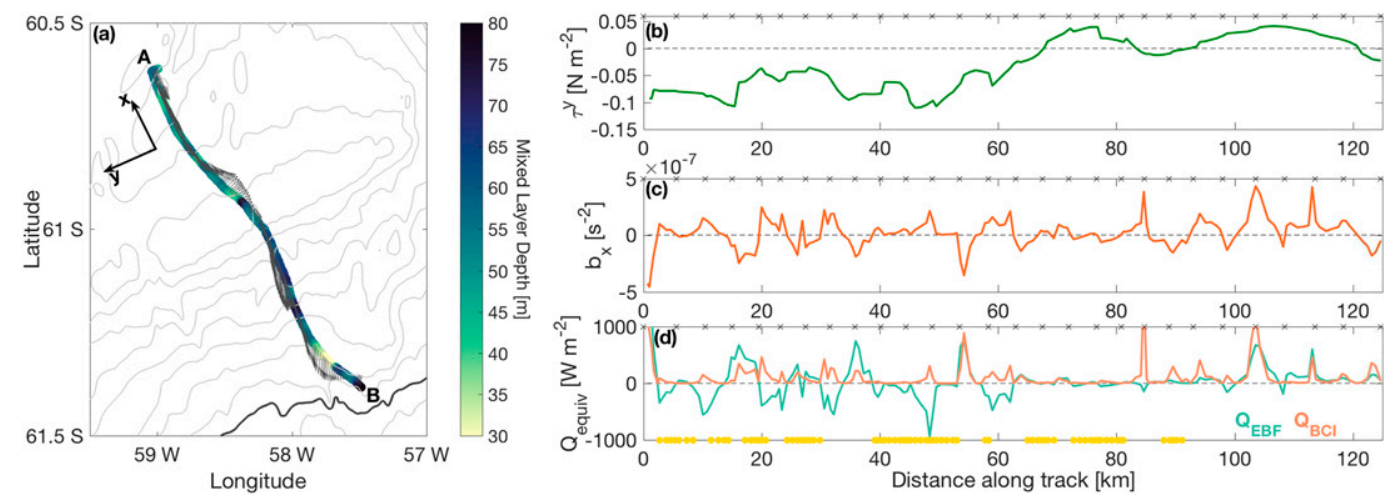

FIG. 6. Sample transect showing calculations of $Q_{\mathrm{EBF}}$ and $Q_{\mathrm{BCI}}$. (a) Mixed layer depth as measured by SG-W over a single cross-shelf transect from A to B. Denoting the winds and light contours give the bathymetry (1000-m isobath is dark). The $x-y$ axis orients the reader for the calculations performed. (b) Alongfront (i.e., perpendicular to glider track) wind stress component. (c) Horizontal buoyancy gradient $b_{x}$, as measured by the Seaglider. (d) Following (6) and (8), $Q_{\mathrm{BCI}}$ (light orange) and $Q_{\mathrm{EBF}}$ (blue-green) over the sample transect. For (b)-(d), the "x" marks on the top axis show the positions of the individual Seaglider dives; yellow circles on bottom axis of (d) show periods of more than $25 \%$ gravitational instability in the mixed layer.

meso- and submesoscale field [Figs. 4c,d; fronts located using AVISO and the contours specified in Kim and Orsi (2014)]. A comparison of the histograms of the horizontal buoyancy gradients in both regions reveals a significant offset between the two curves, with the downstream region more likely to exhibit larger gradients (Fig. 5c). This result is robust to the choice of mixed layer depth criterion. The zonal wind stress is virtually identical between the two regions (Fig. 5b), and therefore this surface forcing alone cannot explain the spatial variability in submesoscale activity.

\section{c. Upper-ocean restratification processes}

Glider data and ECMWF reanalysis winds are used to determine the effects of surface forcing and submesoscale processes on the stratification of the upper ocean, as detailed in section 2e. The parameterizations of Fox-Kemper et al. (2008) and Thomas (2005) are used to calculate equivalent heat fluxes caused by BCI and Ekman buoyancy forcing, respectively (Fig. 6), which are then compared to the surface heat flux $Q_{\text {surf }}$. Since the two gliders are at roughly the same latitude and the cloud cover across the SFZ is similar throughout the deployment, $Q_{\text {surf }}$ is approximately the same across the two regions. There is a strong diurnal cycle, but the forcing over the study period warms the surface ocean with a mean value of $Q_{\text {surf }}=188 \mathrm{~W} \mathrm{~m}^{-2}$. The surface heat flux decreases from summer into early fall during the deployment, with the mean over the first third of the deployment $Q_{\text {surf }}=197 \mathrm{~W} \mathrm{~m}^{-2}$ and the mean over the last third of the deployment $Q_{\text {surf }}=63 \mathrm{~W} \mathrm{~m}^{-2}$. The magnitudes of $Q_{\mathrm{BCI}}$ and $Q_{\mathrm{EBF}}$ are larger, with mean values of 580 and $273 \mathrm{~W} \mathrm{~m}^{-2}$, respectively (Fig. 7).
Upstream of the SFZ, the equivalent heat flux extrema are intermittent, happening roughly once per week, associated with the deeper mixed layers and strong horizontal buoyancy gradients near the shelf break (Figs. 4a,c). Downstream of the SFZ, large values of $Q_{\mathrm{BCI}}$ are more frequent. The large contribution of BCI to the total heat flux (Fig. 7c) suggests that baroclinic instability should have a leading-order impact on setting the mixed layer depth. The contributions of these submesoscale heat fluxes to upper-ocean stratification are explored in the following section.

\section{d. Modeling the observed mixed layers}

The PWP model was previously shown to accurately reproduce mixed layer depths in regions such as the North Pacific (Price et al. 1986) and the tropical IndoPacific (Shinoda and Hendon 1998). However, the ChinStrAP region was characterized by an abundance of lateral processes, which are not captured by the traditional PWP model. We hypothesize that by incorporating the effect of these two-dimensional processes into a modified PWP model, the model will perform better in capturing mixed layer depth variability. Indeed, the unmodified PWP model results in mixed layer depths that are significantly deeper than those observed by the glider. For SG-E, the PWP model outputs a mean mixed layer depth and standard deviation of $229 \pm 33 \mathrm{~m}$, compared to $119 \pm 86 \mathrm{~m}$ as observed by the glider (a $92 \%$ error in mean and a $62 \%$ error in standard deviation of the mixed layer). Not only is the modeled mean mixed layer depth significantly deeper than the actual mixed layer, the mixed layer variance is not well captured by the PWP model. 

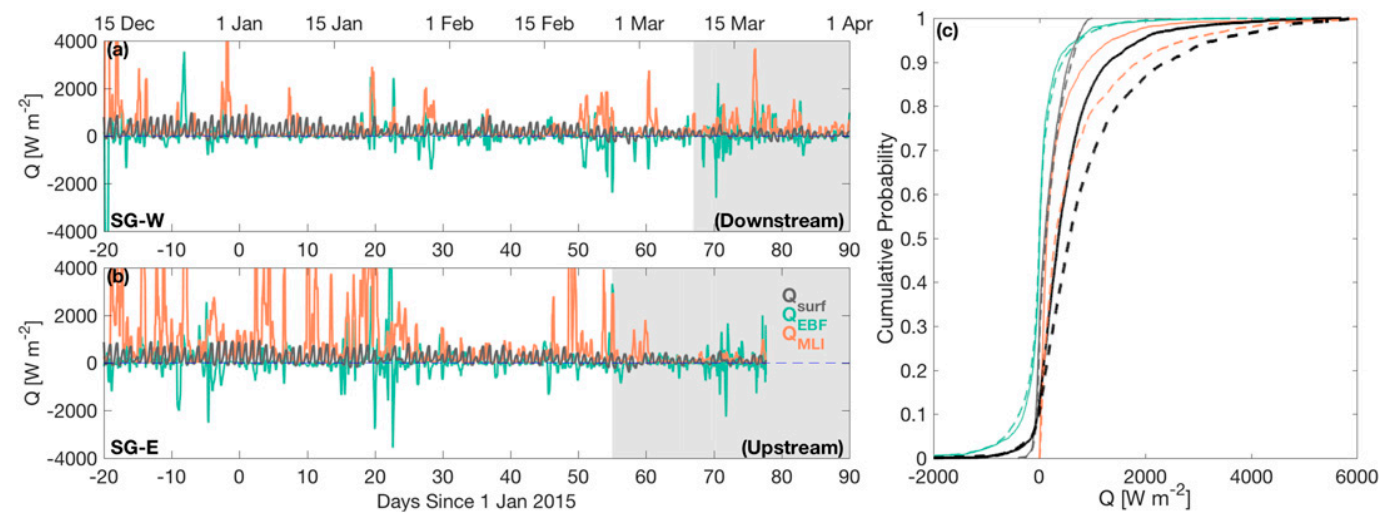

FIG. 7. Time series of heat forcing and equivalent buoyancy fluxes for (a) SG-W and (b) SG-E: $Q_{\text {surf }}$ (gray), $Q_{\mathrm{MLI}}$ (orange), and $Q_{\mathrm{EBF}}$ (green). Positive (negative) values are heat into (out of) the ocean. Gray boxes indicate times when SG-W (SG-E) is downstream (upstream) of the SFZ. (c) Cumulative distribution of $Q_{\text {surf }}$ (gray), $Q_{\text {MLI }}$ (orange), $Q_{\mathrm{EBF}}$ (green), and total heat flux (black) for SG-W (solid) and SG-E (dashed).

To improve the performance of the PWP model, we accounted for the effects of submesoscale motions via the parameterizations for $Q_{\mathrm{EBF}}$ and $Q_{\mathrm{BCI}}$ (described in section 2e). These two terms were combined into a forcing term that is applied equally over the mixed layer depth at each time step in the model $Q_{\text {sub }}$, given as

$$
Q_{\mathrm{sub}}=Q_{\mathrm{EBF}}+Q_{\mathrm{BCI}} \text {. }
$$

The result of this mPWP model is closer to the observations in terms of both mean mixed layer depth and variance, providing mixed layers of $177 \pm 81 \mathrm{~m} \mathrm{(a} 6 \%$ difference from the standard deviation of the glider observations, although still a $48 \%$ difference from the mean of the observations). Although the individual mixed layer shoaling/deepening events do not match up between the observations and the mPWP model, the modified model does capture much of the character of the observed mixed layer, with large variations of mixed layer depth over relatively short time scales (Fig. 8). The model output is also consistent with our findings that the submesoscales are dominantly restratifying over the period of deployment and indicates that accounting for the submesoscale motions is critical to correctly model mixed layer depths and variability.

Shoaling of the mean mixed layer throughout the sample period can be observed in both the PWP and mPWP models, although the effect is much more pronounced for the mPWP configuration. Large et al. (1994) discuss the need for advection of cold water and salt into mixed layer models to offset the long-term drifts caused by net surface heating/freshwater flux. The mPWP model exhibits a larger shoaling over the model run as there is a greater (equivalent) heat flux being applied to the surface. The mPWP model captures the transition from deep to shallow mixed layers observed by the glider moving from December/January into the end of the summer, while the standard PWP model does not. Remaining differences between the observations and the mPWP model can be attributed to other processes, such as Langmuir circulations, or wave-forced turbulence, which have been shown by Belcher et al. (2012) to play a significant role in setting mixed layer
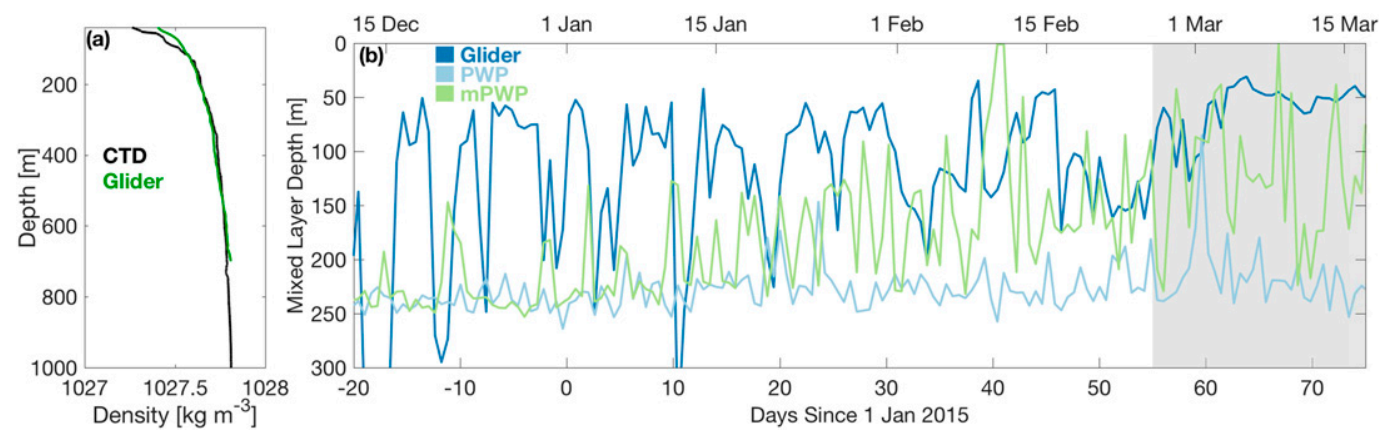

FIG. 8. (a) Density profile from CTD (black) and glider SG-E (green). (b) Comparison of mixed layer depth from observations from SG-E (dark blue), PWP model (light blue), and mPWP model. The gray area indicates the period when glider SG-E crossed to the western (upstream) side of the SFZ. 


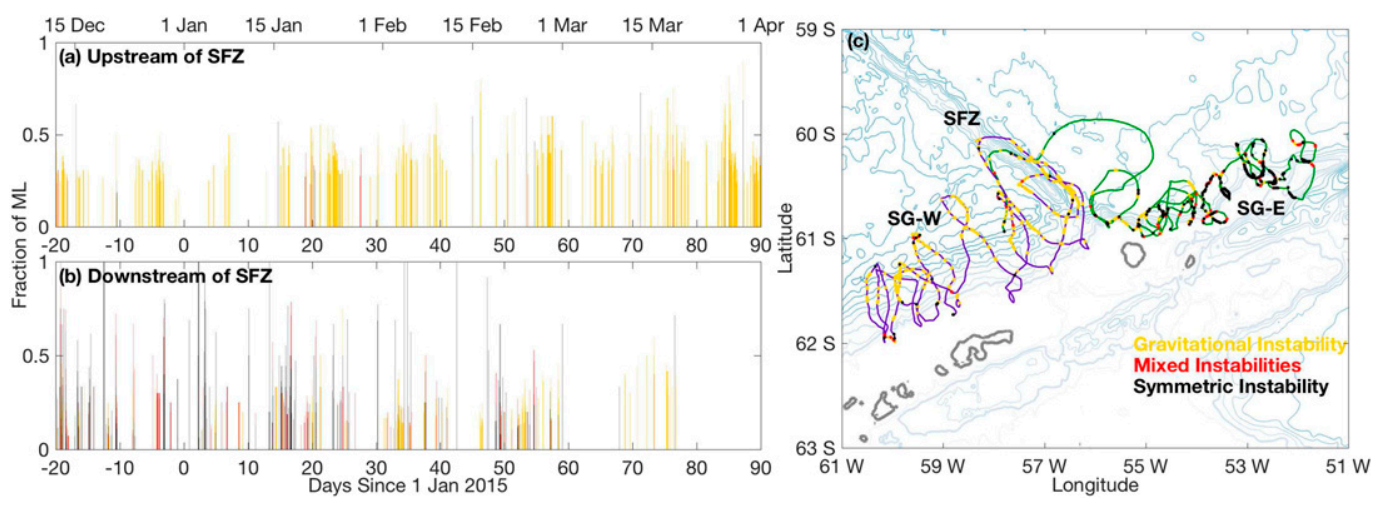

FIG. 9. Time series of submesoscale instability preconditioning (a) upstream and (b) downstream of the SFZ for gravitational (yellow), mixed gravitational/symmetric (red), and symmetric (black) instabilities. (c) Map of the study area (1000-m isobath is dark) with glider tracks for SG-W (purple) and SG-E (green). The series has been filtered such that more than $20 \%$ of the mixed layer is conditioned for a given instability at a given time step.

depths in the Southern Ocean. Similarly, lateral advection and large-scale gradients in the background stratification are not captured in the model and may also help to explain some of the remaining discrepancies.

\section{e. Variation of instabilities}

There is also significant variation between the two regions with regard to the types of instabilities the mixed layer is conditioned to undergo, as described in section $2 \mathrm{e}$ (Fig. 9). A comparison of the two time series of submesoscale instabilities shows that the region upstream of the SFZ is more susceptible to gravitational instability. In contrast, the area downstream of the SFZ experiences frequent, but intermittent, episodes that would indicate symmetric instability, sometimes extending through the whole mixed layer (Fig. 9b). The spatial pattern of instabilities (Fig. 9c) shows that symmetric instability is favored both on- and off-shelf downstream. Upstream of the SFZ, periods of conditioning of $25 \%$ or more of the mixed layer toward gravitational instability occur $28 \%$ of the time. This is especially common far from the shelf break. These classifications are consistent with Adams et al. (2017), who observed conditions suitable for gravitational and symmetric instabilities during early fall in the Scotia Sea. We propose that the enhancement of gravitational instability upstream of the SFZ can in part be attributed to the persistent forcing of the ACC's topographically steered fronts by down-front winds. On a dive-by-dive basis, it may not be possible to identify forcing factors contributing to a certain type of instability conditioning; however, there is a larger-scale pattern aligning periods of gravitational instability with higher EBF off the shelf (as compared to on shelf), as seen in Fig. 6. We leave a more in-depth investigation of the mechanisms behind the specific instabilities to a future work.

\section{f. Validation of glider-based PV calculations}

The calculation of PV from the Seagliders requires the gliders to be piloted perpendicular to the orientation of the front. This requires the following assumptions: (i) variation in the alongfront direction is negligible, and (ii) velocities across the front are negligible. With the additional assumption that vertical velocities are small, we obtain an expression for observational PV [(2)]. To verify the validity of these simplifications, the LLC $1 / 48^{\circ} \mathrm{GCM}$ was utilized. Three subdomains over the deployment area were extracted from the model output, comprising over 150 sections. The full Ertel PV and the observational PV calculated from these transects show many of the same structures; the amplitude of the observational PV estimates tend to be smaller than the full PV, especially in the mixed layer (Figs. 10a,b). These calculations were performed within the top-200-m depth using snapshots every two hours over a period of 5 days for each subdomain. Comparing the signs of the respective PV calculations reveals the same sign at $92.3 \%$ of all these points in space and time. False positives, or times when the observational PV indicates instability but the full PV does not, occur only $2.1 \%$ of the time. As the three subdomains were chosen from multiple regions with different dynamics, and calculations were performed for a range of days and times, this provides additional confidence in the assumptions and, thus, the PV and instability calculations.

\section{Discussion}

\section{a. Summer submesoscale activity}

Previous studies have shown that the intensity of submesoscale activity can undergo a strong seasonal cycle, linked to changes in the mixed layer depth and in some cases to mesoscale stirring (Sasaki et al. 2014; Callies et al. 

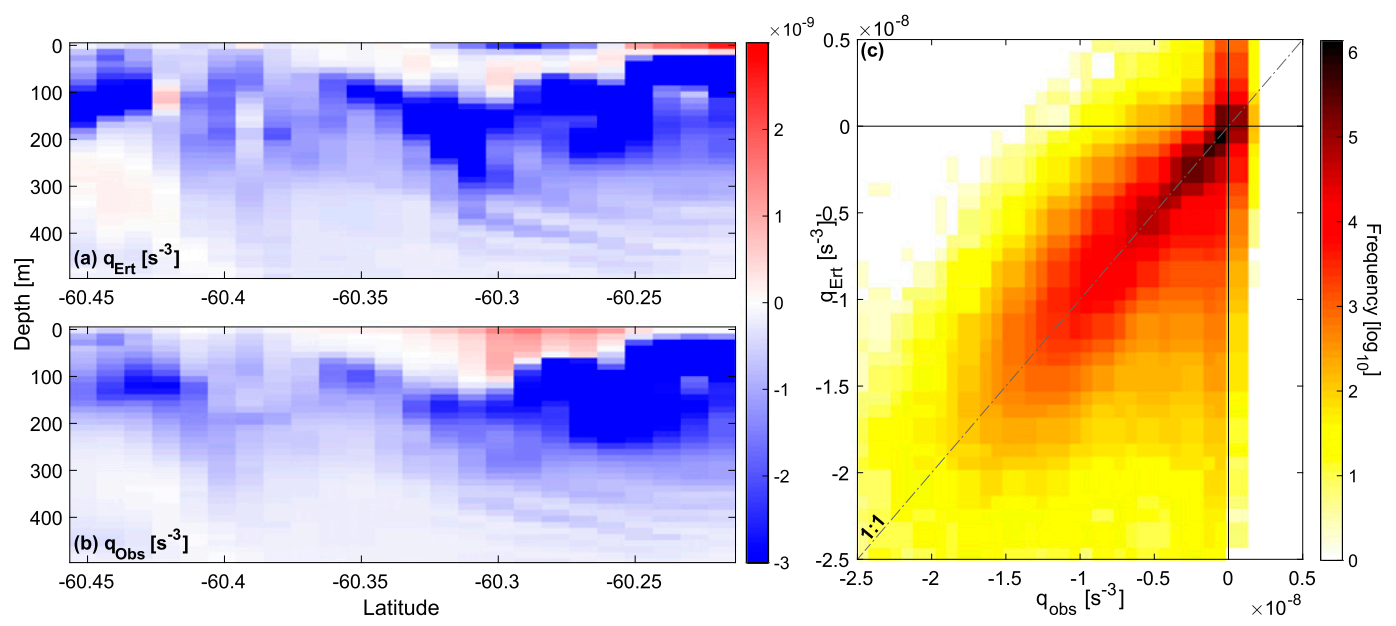

FIG. 10. Representative potential vorticity section as calculated from the $1 / 48^{\circ} \mathrm{LLC}$ model configuration. (a) The $q_{\text {Ertel }}$, the full Ertel PV as given by (1), and (b) $q_{\text {Obs }}$, the observational PV as given by (2). This transect coincides with the downstream section highlighted in Fig. 1b. (c) Histogram heat map (log scale) of $q_{\text {Ertel }}$ and $q_{\text {Obs }}$ from the top $200 \mathrm{~m}$ of 150 modeled transects.

2015; Buckingham et al. 2016). Instances of symmetric instability have been observed in western boundary currents (D'Asaro et al. 2011; Thomas et al. 2016), and conditions suitable for symmetric instability have been documented in the subtropical open ocean in both the Atlantic (Thompson et al. 2016) and Pacific (Hosegood et al. 2013) basins. However, these previous studies either have focused explicitly on the winter season or have found a particularly vigorous submesoscale field during the winter months. This study, in contrast, took place during the summer months and into the early fall, when shallower mixed layers and increased stratification have previously been found to suppress submesoscale activity in other ocean basins. Our findings of an active submesoscale in the Southern Ocean corroborate the results of du Plessis et al. (2017), who conducted a similar survey in the subantarctic zone in spring-summertime.

In the ChinStrAP study, we found evidence supporting the existence of symmetric instability in Southern Drake Passage during the austral summer (DecemberMarch). Favorable conditions for symmetric instability were found downstream of the SFZ for the duration of the study. The likely presence and prevalence of submesoscale instabilities, even in the summertime, requires a reevaluation of the way that dynamics of this scale are considered in climate and circulation models, for example, via new parameterizations for SI put forth by Bachman et al. (2017a). As seen in Klein and Lapeyre (2009), density gradients at the submesoscale can be responsible for up to $50 \%$ of the vertical exchange between the mixed layer and the thermocline below. Combined with the active summertime submesoscale presented here, this suggests that current models may be underestimating the strength of the dynamical component of the Southern Ocean biological pump.

\section{b. Spatial variations: Upstream vs downstream of Shackleton Fracture Zone}

Three key components contribute to the parameterizations of $Q_{\mathrm{EBF}}$ and $Q_{\mathrm{BCI}}$ : mixed layer depth; horizontal buoyancy gradient $b_{x}$, indicative of mesoscale and submesoscale stirring; and wind stress-front orientation $\tau^{y}$. While the mode of the mixed layer depth (histogram peak in Fig. 5a) is similar across our study region, the distribution of mixed layer depths upstream of the SFZ is much tighter, while downstream of the SFZ, there is a long tail on the distribution (Fig. 5a). The other main difference between the regions is in the horizontal (along track) buoyancy gradient $b_{x}$, where there is an offset between the histograms, with stronger buoyancy gradients downstream of the SFZ (Fig. 5b).

The differences in horizontal buoyancy gradients upstream and downstream of the SFZ suggest different dynamical regimes, which imply differing magnitudes, types, and frequency of submesoscale instabilities. Upstream of the SFZ, there are strong events of EBF and/or BCI with a significant impact on the equivalent heat budget of the upper ocean (Figs. 7a,c), but these events are localized to a narrow region associated with the SBACC. The topographically constrained fronts and the persistence of the westerly (down front) winds generate the gravitational instabilities classified in Fig. 9. In contrast, these same events downstream of the SFZ are much more frequent and occur over a broader spatial extent, owing to both the larger buoyancy gradients and deeper mixed layers, both of which precondition the upper ocean for symmetric 

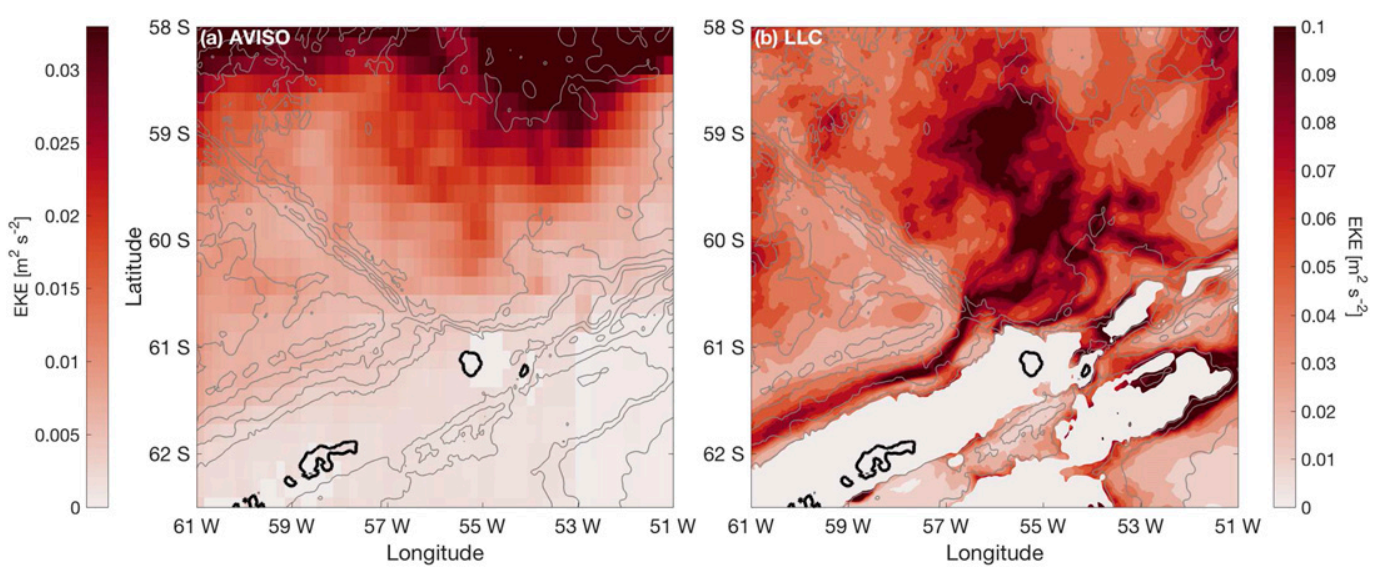

FIG. 11. Surface eddy kinetic energy $\left(\mathrm{m}^{2} \mathrm{~s}^{-2}\right)$ over the ChinStrAP study region (December-March). Gray contours underneath show the bathymetry of the study region: calculated from (a) AVISO $1 / 6^{\circ}$ altimetry data from 2006-16 and (b) the 1/48 LLC MITgem for December 2011-March 2012. Values have been blanked out for bathymetry shallower than $750 \mathrm{~m}$. EKE in (a) has a maximum value that is $1 / 3$ the maximum of EKE in (b) due to the differing resolutions of the two datasets.

instability. Critically, these differences occur despite experiencing the same surface forcing fields.

We propose that the increased submesoscale activity downstream of the SFZ is due to two main factors: spatial variations in eddy kinetic energy (EKE) and upper-ocean stratification. Differences in the surface EKE are captured clearly in both satellite altimetry data as well as output from the LLC (Fig. 11). These patterns in EKE are strongly influenced by the bathymetry, both due to the deflection of the SBACC over the SFZ and the retroflection of the ASF exiting the Weddell Sea. Both of these processes tend to generate mesoscale eddies that will increase lateral stirring and induce variability at submesoscales. The LLC shows how the ACC becomes unstable as it passes through the SFZ, leading to an increase in EKE downstream. This signal is weaker in the observed sea surface height variability owing to the much lower resolution of AVISO compared to the LLC, but the observations still show that the average summertime EKE is enhanced downstream of the SFZ (Fig. 11a). In addition to EKE, the large-scale circulation supports weaker vertical stratification of the upper ocean downstream of the SFZ. The main cause of this is the shoreward penetration of AASW upstream of the SFZ, whereas the northward deflection of the SBACC limits its southward extension downstream. Thus, downstream of the SFZ, relatively homogeneous upper-ocean density contributes to lower PV and deeper mixed layers that store more potential energy and may thus be more prone to submesoscale instabilities.

\section{c. Impact and limitations of the study}

Separating spatial and temporal variability in the glider data is a significant challenge. The experimental design of the field program acted to counteract this in several ways. First, the simultaneous piloting of the gliders upstream and downstream of the SFZ allows the direct comparison of dynamics and water-mass properties between the two regions. Each glider also occupied transects in approximately the same location over multiple weeks; these multiply occupied sections support that variability is predominantly spatial, rather than temporal. The glider capabilities (e.g., speed through the water) also influence our interpretation of these time series. First, the time to complete a full transect is long compared to the time scales of submesoscale dynamics. Thus, we emphasize that this study provides a statistical survey of the region and not a perfect snapshot of the dynamical regime; we stress the intercomparison of patterns, rather than the absolute magnitudes. The second is a practical matter; the glider often flew at a speed comparable to or less than that of the depth-averaged current, making it difficult to fly the glider perpendicular to the front.

The key assumption in our calculations of equivalent heat fluxes and Richardson numbers was that the gliders were flown perpendicular to the frontal structure of the ACC, which allowed us to simplify PV into a two-dimensional expression. This was more successful upstream of the SFZ than downstream, with SG-W maintaining relatively straight trajectories across the continental shelf for the majority of the deployment (Fig. 1). Downstream of the SFZ, the frontal structure is less well defined. Because the glider tracks are less perpendicular to the shelf, it is more difficult to know the glider's orientation with respect to the fronts. Critically, though, the LLC model does reproduce intermittent regions in the surface mixed layer where $\mathrm{PV}>0$ in the 
summertime, consistent with our observations. Furthermore, analysis of the LLC also demonstrates higher propensities for conditioning toward gravitational instability upstream of the SFZ and toward symmetric instability downstream of the SFZ.

Despite the limitations of this study, the results provide valuable insight into submesoscale variability in one region of the Southern Ocean. Most notably, although previous work has shown the importance of submesoscale activity (e.g., Klein and Lapeyre 2009; Rosso et al. 2014), this is among the first studies to show such ubiquitous submesoscale dynamics during the summertime, a period when shallow mixed layers and increased stratification should act to prohibit the instabilities explored in this study (see also du Plessis et al. 2017). The comparison of observed mixed layers and those calculated by the PWP bulk mixed layer model demonstrate the importance of these dynamics in setting the mixed layer depth and stratification of the upper ocean. We have also shown the existence of two very different submesoscale dynamical regimes separated by a relatively small distance; conditioning by the background flow is largely influenced by the underlying bathymetry. We stress the need to characterize regional variability in the ACC. The abrupt change in submesoscale character due to topography is another example of localized "hot spots" that have a dynamical influence on the Southern Ocean (Abernathey and Cessi 2014; Thompson and Naveira Garabato 2014; Dufour et al. 2015; Viglione and Thompson 2016; Tamsitt et al. 2016). We propose that similar dynamical shifts may occur in other regions of the Southern Ocean with large topographic features, for example, Kerguelen Plateau and the Pacific-Antarctic Ridge (Rosso et al. 2014), which has implications for the localization of $\mathrm{CO}_{2}$ uptake in the Southern Ocean. In particular, because of the fine spatial structure of these upper-ocean processes, long time series of $\mathrm{pCO}_{2}$ concentrations in specific locations, such as Drake Passage (Takahashi et al. 2009), may provide misleading information about the Southern Ocean carbon cycle if simply extrapolated circumpolarly.

\section{Conclusions}

Two Seagliders were deployed north of the Antarctic Peninsula from December 2014 to April 2015, sampling both up- and downstream of the Shackleton Fracture Zone (SFZ). Sampling at a mean horizontal resolution of $1.6 \mathrm{~km}$, this study resolves the upper-ocean submesoscale density structure of a key region of the ocean for water-mass ventilation and modification (Sallée et al. 2010; Abernathey et al. 2016), as well as shelf-slope exchange and water-mass modification (Ruan et al. 2017). Although the mesoscale eddy stirring, strong wind forcing, deep mixed layers, and persistent fronts would suggest the Southern Ocean to be a hotbed for submesoscale activity, little observational work has been undertaken here to validate numerical simulations (Rocha et al. 2016; Adams et al. 2017). In this work, we present evidence for an active submesoscale field, even in summer months, but distinct geographical differences in the characteristics of these submesoscale motions. The conditions for symmetric instability are found almost exclusively downstream of the SFZ, suggesting fundamental differences in the dynamics of the regions on either side of the SFZ. The primary differences between the two regions are deeper mixed layers and stronger lateral buoyancy gradients downstream of the SFZ. Together, these contribute to the preconditioning of the downstream region for increased submesoscale activity.

Finally, comparisons were made between the glider observations and two different models. First, the 1D PWP bulk mixed layer model was used in an attempt to replicate the time-evolving mixed layer depth. This model was seen to diverge from the observations because of its exclusion of submesoscale and other threedimensional processes. When parameterized fluxes, $Q_{\mathrm{EBF}}$ and $Q_{\mathrm{BCI}}$, were added into the surface forcing, the modified PWP model was more accurate in representing the variability in the mixed layer depth time series, although the mean values were still $50 \%$ larger than the observations. PV calculated from the glider observations was compared to the full Ertel PV as diagnosed from the $1 / 48^{\circ}$ LLC model. The LLC was also subsampled and used to calculate the PV using the same simplifications as when calculating the observed PV from the glider. These results showed that while some caution must be used in calculating PV from gliders, the sign of the observed PV is predominantly the same as the sign of the full PV (in $92.3 \%$ of instances, both PV calculations had the same sign).

This work provides evidence that the submesoscale is highly active in the Southern Ocean even during the summertime, significantly altering the stratification of the upper ocean with implications for carbon capture and the biological pump. The intermittency of these events as well as the size of the variations over short spatial scales suggests that this is a complex phenomenon that will remain challenging to represent in numerical models not focused on localized regions; this is particularly true for the role of submesoscale on air-sea coupling. The comparison of these observations to a high-resolution model validates the use of gliders to study instabilities at this scale. 
Acknowledgments. GAV and AFT were supported by NSF Award OPP-1246460. JS was supported by NSF Award OPP-1246160. SS thanks the following funding agencies: a Wallenberg Academy Fellowship (WAF 2015.0186) and the South African National Research Foundation (NRF), Grant SNA14071475720. The Group for High Resolution Sea Surface Temperature (GHRSST) Multiscale Ultra-High-Resolution (MUR) SST data were obtained from the NASA EOSDIS Physical Oceanography Distributed Active Archive Center (PO.DAAC) at the Jet Propulsion Laboratory, Pasadena, California (https://doi.org/10.5067/GHGMR4FJ01). The ERA-Interim data were obtained from ECMWF. The authors thank the Antarctic Support Contract staff as well as the captains and crews of the ARSV Laurence M. Gould and the RRS Ernest Shackleton for their support during the deployment and recovery cruises.

\section{REFERENCES}

Abernathey, R., and P. Cessi, 2014: Topographic enhancement of eddy efficiency in baroclinic equilibration. J. Phys. Oceanogr., 44, 2107-2126, https://doi.org/10.1175/JPO-D-14-0014.1.

— I. Cerovecki, P. R. Holland, E. Newsom, M. Mazloff, and L. D. Talley, 2016: Water-mass transformation by sea ice in the upper branch of the Southern Ocean overturning. Nat. Geosci., 9, 596-601, https://doi.org/10.1038/ngeo2749.

Adams, K. A., P. Hosegood, J. R. Taylor, J.-B. Sallée, S. Bachman, R. Torres, and M. Stamper, 2017: Frontal circulation and submesoscale variability during the formation of a Southern Ocean mesoscale eddy. J. Phys. Oceanogr., 47, 1737-1753, https://doi.org/10.1175/JPO-D-16-0266.1.

Adcroft, A., C. Hill, and J. A. Marshall, 1997: Representation of topography by shaved cells in a height coordinate ocean model. Mon. Wea. Rev., 125, 2293-2315, https://doi.org/ 10.1175/1520-0493(1997)125<2293:ROTBSC > 2.0.CO;2.

Bachman, S. D., B. Fox-Kemper, J. R. Taylor, and L. N. Thomas, 2017a: Parameterization of frontal symmetric instabilities. I: Theory for resolved fronts. Ocean Modell., 109, 72-95, https:// doi.org/10.1016/j.ocemod.2016.12.003.

_ J. R. Taylor, K. A. Adams, and P. J. Hosegood, 2017b: Mesoscale and submesoscale effects on mixed layer depth in the Southern Ocean. J. Phys. Oceanogr., 47, 2173-2188, https:// doi.org/10.1175/JPO-D-17-0034.1.

Barré, N., C. Provost, N. Sennechael, and J. H. Lee, 2008: Circulation in the Ona Basin, southern Drake Passage. J. Geophys. Res., 113, C04033, https://doi.org/10.1029/2007JC004549.

Belcher, S. E., and Coauthors, 2012: A global perspective on Langmuir turbulence in the ocean surface boundary layer. Geophys. Res. Lett., 39, L18605, https://doi.org/10.1029/ 2012 GL052932.

Boccaletti, G., R. Ferrari, and B. Fox-Kemper, 2007: Mixed layer instabilities and restratification. J. Phys. Oceanogr., 37, 22282250, https://doi.org/10.1175/JPO3101.1.

Buckingham, C. E., and Coauthors, 2016: Seasonality of submesoscale flows in the ocean surface boundary layer. Geophys. Res. Lett., 43, 2118-2126, https://doi.org/10.1002/ 2016GL068009.
Callies, J., R. Ferrari, J. M. Klymak, and J. Gula, 2015: Seasonality in submesoscale turbulence. Nat. Commun., 6, 6862, https:// doi.org/10.1038/ncomms7862.

Capet, X., J. C. McWilliams, M. J. Molemaker, and A. F. Shchepetkin, 2008: Mesoscale to submesoscale transition in the California Current System. Part I: Flow structure, eddy flux, and observational tests. J. Phys. Oceanogr., 38, 29-43, https://doi.org/10.1175/2007JPO3671.1.

Chao, Y., Z. Li, J. D. Farrara, and P. Huang, 2009: Blending sea surface temperatures from multiple satellites and in situ observations for coastal oceans. J. Atmos. Oceanic Technol., 26, 1415-1426, https://doi.org/10.1175/2009JTECHO592.1.

Daru, V., and C. Tenaud, 2004: High order one-step monotonicitypreserving schemes for unsteady compressible flow calculations. J. Comput. Phys., 193, 563-594, https://doi.org/10.1016/ j.jcp.2003.08.023.

D'Asaro, E., C. Lee, L. Rainville, R. Harcourt, and L. Thomas, 2011: Enhanced turbulence and energy dissipation at ocean fronts. Science, 332, 318-322, https://doi.org/10.1126/ science. 1201515.

Dee, D. P., and Coauthors, 2011: The ERA-Interim reanalysis: Configuration and performance of the data assimilation system. Quart. J. Roy. Meteor. Soc., 137, 553-597, https://doi.org/ 10.1002/qj.828.

Dufour, C. O., and Coauthors, 2015: Role of mesoscale eddies in cross-frontal transport of heat and biogeochemical tracers in the Southern Ocean. J. Phys. Oceanogr., 45, 3057-3081, https://doi.org/10.1175/JPO-D-14-0240.1.

du Plessis, M., S. Swart, I. J. Ansorge, and A. Mahadevan, 2017: Submesoscale processes promote seasonal restratification in the Subantarctic Ocean. J. Geophys. Res. Oceans, 122, 29602975, https://doi.org/10.1002/2016JC012494.

Erickson, Z. K., A. F. Thompson, N. Cassar, J. Sprintall, and M. R. Mazloff, 2016: An advective mechanism for deep chlorophyll maxima formation in southern Drake Passage. Geophys. Res. Lett., 43, 10 846-10 855, https://doi.org/10.1002/2016GL070565.

Flexas, M. M., M. P. Schodlok, L. Padman, D. Menemenlis, and A. H. Orsi, 2015: Role of tides on the formation of the Antarctic Slope Front at the Weddell-Scotia Confluence. J. Geophys. Res. Oceans, 120, 3658-3680, https://doi.org/ 10.1002/2014JC010372.

Fox-Kemper, B., and D. Menemenlis, 2008: Can large eddy simulation techniques improve mesoscale rich ocean models? Ocean Modeling in an Eddying Regime, M. Hecht and H. Hasumi, Eds., Amer. Geophys. Union, 319-338.

- R. Ferrari, and R. Hallberg, 2008: Parameterization of mixed layer eddies. Part I: Theory and diagnosis. J. Phys. Oceanogr., 38, 1145-1165, https://doi.org/10.1175/2007JPO3792.1.

Gill, A. E., 1973: Circulation and bottom water production in the Weddell Sea. Deep-Sea Res., 20, 111-140, https://doi.org/ 10.1016/0011-7471(73)90048-X.

Haine, T. W., and J. Marshall, 1998: Gravitational, symmetric, and baroclinic instability of the ocean mixed layer.J. Phys. Oceanogr., 28, 634-658, https://doi.org/10.1175/1520-0485(1998)028<0634: $\mathrm{GSABIO}>2.0 . \mathrm{CO} ; 2$.

Heywood, K. J., A. C. Naveira Garabato, D. P. Stevens, and R. D. Muench, 2004: On the fate of the Antarctic Slope Front and the origin of the Weddell Front. J. Geophys. Res., 109, C06021, https://doi.org/10.1029/2003JC002053.

Hill, C., D. Menemenlis, B. Ciotti, and C. Henze, 2007: Investigating solution convergence in a global ocean model using a 2048processor cluster of distributed shared memory machines. Sci. Program., 15, 107-115, https://doi.org/10.1155/2007/458463. 
Hosegood, P. J., M. C. Gregg, and M. H. Alford, 2013: Wind-driven submesoscale subduction at the North Pacific subtropical front. J. Geophys. Res. Oceans, 118, 5333-5352, https://doi.org/ 10.1002/jgrc. 20385.

Jacobs, S. S., 1991: On the nature and significance of the Antarctic Slope Front. Mar. Chem., 35, 9-24, https://doi.org/10.1016/ S0304-4203(09)90005-6.

Kim, Y. S., and A. H. Orsi, 2014: On the variability of Antarctic Circumpolar Current fronts inferred from 1992-2011 altimetry. J. Phys. Oceanogr., 44, 3054-3071, https://doi.org/10.1175/ JPO-D-13-0217.1.

Klein, P., and G. Lapeyre, 2009: The oceanic vertical pump induced by mesoscale and submesoscale turbulence. Annu. Rev. Mar. Sci., 1, 351-375, https://doi.org/10.1146/annurev.marine.010908.163704.

Large, W. G., J. C. McWilliams, and S. C. Doney, 1994: Oceanic vertical mixing: a review and a model with a nonlocal boundary layer parameterization. Rev. Geophys., 32, 363-403, https://doi.org/10.1029/94RG01872.

Lenn, Y.-D., and T. K. Chereskin, 2009: Observations of Ekman currents in the Southern Ocean. J. Phys. Oceanogr., 39, 768779, https://doi.org/10.1175/2008JPO3943.1.

Losch, M., D. Menemenlis, J.-M. Campin, P. Heimback, and C. Hill, 2010: On the formulation of sea-ice models. Part 1: Effects of different solver implementations and parameterizations. Ocean Modell., 33, 129-144, https://doi.org/10.1016/ j.ocemod.2009.12.008.

Mahadevan, A., and A. Tandon, 2006: An analysis of mechanisms for submesoscale vertical motion at ocean fronts. Ocean Modell., 14, 241-256, https://doi.org/10.1016/j.ocemod.2006.05.006.

_, - and R. Ferrari, 2010: Rapid changes in mixed layer stratification driven by submesoscale instabilities and winds. J. Geophys. Res., 115, C03017, https://doi.org/10.1029/ 2008JC005203.

—, E. D'Asaro, C. Lee, and M. J. Perry, 2012: Eddydriven stratification initiates North Atlantic spring phytoplankton blooms. Science, 337, 54-58, https://doi.org/10.1126/ science. 1218740 .

Marshall, D., 1997: Subduction of water masses in an eddying ocean. J. Mar. Res., 55, 201-222, https://doi.org/10.1357/ 0022240973224373.

Marshall, J. A., A. Adcroft, C. Hill, L. Perelman, and C. Heisey, 1997: A finite-volume, incompressible Navier Stokes model for studies of the ocean on parallel computers. J. Geophys. Res., 102, 5753-5766, https://doi.org/10.1029/96JC02775.

McWilliams, J. C., 2016: Submesoscale currents in the ocean. Proc. Roy. Soc. London, 472A, 20160117, https://doi.org/10.1098/ rspa.2016.0117.

Menemenlis, D., I. Fukumori, and T. Lee, 2005: Using Green's functions to calibrate an ocean general circulation model. Mon. Wea. Rev., 133, 1224-1240, https://doi.org/10.1175/ MWR2912.1.

- , J.-M. Campin, P. Heimbach, C. Hill, T. Lee, A. Nguyen, M. Schodlok, and H. Zhang, 2008: ECCO2: High resolution global ocean and sea ice data synthesis. Mercator Ocean Quarterly Newsletter, No. 31, Mercator Ocean, Saint-Agne, France, 13-21, http://ecco2.org/manuscripts/reports/ECCO2_Mercator.pdf.

Meredith, M. P., and Coauthors, 2011: Sustained monitoring of the Southern Ocean at Drake Passage: Past achievements and future priorities. Rev. Geophys., 49, RG4005, https://doi.org/ 10.1029/2010RG000348.

Monterey, G. I., and S. Levitus, 1997: Seasonal Variability of Mixed Layer Depth for the World Ocean. NOAA Atlas NESDIS 14, $96 \mathrm{pp}$.
Orsi, A. H., T. Whitworth, and W. D. Nowlin, 1995: On the meridional extent and fronts of the Antarctic Circumpolar Current. Deep-Sea Res. I, 42, 641-673, https://doi.org/10.1016/ 0967-0637(95)00021-W.

Palmer, M., D. Gomis, M. M. Flexas, G. Jordà, L. Jullion, T. Tsubouchi, and A. C. N. Garabato, 2012: Water mass pathways and transports over the South Scotia Ridge west of $50^{\circ} \mathrm{W}$. Deep-Sea Res. I, 59, 8-24, https://doi.org/10.1016/j.dsr.2011.10.005.

Patterson, S. L., and H. A. Sievers, 1980: The Weddell-Scotia Confluence. J. Phys. Oceanogr., 10, 1584-1610, https://doi.org/ 10.1175/1520-0485(1980)010<1584:TWSC $>2.0$. CO 2 .

Paulson, C. A., and J. J. Simpson, 1977: Irradiance measurements in the upper ocean. J. Phys. Oceanogr., 7, 952-956, https://doi.org/ 10.1175/1520-0485(1977)007<0952:IMITUO > 2.0.CO;2.

Price, J. F., R. A. Weller, and R. Pinkel, 1986: Diurnal cycling: Observations and models of the upper ocean response to diurnal heating, cooling, and wind mixing. J. Geophys. Res., 91, 8411-8427, https://doi.org/10.1029/JC091iC07p08411.

Rocha, C. B., T. K. Chereskin, S. T. Gille, and D. Menemenlis, 2016: Mesoscale to submesoscale wavenumber spectra in Drake Passage. J. Phys. Oceanogr., 46, 601-620, https:// doi.org/10.1175/JPO-D-15-0087.1.

Rosso, I., A. M. Hogg, P. G. Strutton, A. E. Kiss, R. Matear, A. Klocker, and E. van Sebille, 2014: Vertical transport in the ocean due to sub-mesoscale structures: Impacts in the Kerguelen region. Ocean Modell., 80, 10-23, https://doi.org/ 10.1016/j.ocemod.2014.05.001.

Ruan, X., A. F. Thompson, M. M. Flexas, and J. Sprintall, 2017: Contribution of topographically generated submesoscale turbulence to Southern Ocean overturning. Nat. Geosci., 10, 840845, https://doi.org/10.1038/ngeo3053.

Sallée, J.-B., K. G. Speer, and S. R. Rintoul, 2010: Zonally asymmetric response of the Southern Ocean mixed-layer depth to the southern annular mode. Nat. Geosci., 3, 273-279, https:// doi.org/10.1038/ngeo812.

Sasaki, H., P. Klein, B. Qiu, and Y. Sasai, 2014: Impact of oceanicscale interactions on the seasonal modulation of ocean dynamics by the atmosphere. Nat. Commun., 5, 5636, https://doi.org/ 10.1038/ncomms6636.

Shcherbina, A. Y., E. A. D'Asaro, C. M. Lee, J. M. Klymak, M. J. Molemaker, and J. C. McWilliams, 2013: Statistics of vertical vorticity, divergence, and strain in a developed submesoscale turbulence field. Geophys. Res. Lett., 40, 4706-4711, https:// doi.org/10.1002/grl.50919.

Shinoda, T., and H. H. Hendon, 1998: Mixed layer modeling of intraseasonal variability in the tropical western Pacific and Indian Oceans. J. Climate, 11, 2668-2685, https://doi.org/ 10.1175/1520-0442(1998)011<2668:MLMOIV>2.0.CO;2.

Smith, W. H. F., and D. T. Sandwell, 1997: Global sea floor topography from satellite altimetry and ship depth soundings. Science, 277, 1957-1962, https://doi.org/10.1126/ science.277.5334.1956.

Sprintall, J., 2003: Seasonal to interannual upper-ocean variability in the Drake Passage. J. Mar. Res., 61, 27-57, https://doi.org/ $10.1357 / 002224003321586408$.

Su, Z., J. Wang, P. Klein, A. F. Thompson, and D. Menemenlis, 2018: Ocean submesoscales as a key component of the global heat budget. Nat. Commun., 9, 775, https://doi.org/10.1038/ s41467-018-02983-w.

Takahashi, T., and Coauthors, 2009: Climatological mean and decadal change in surface ocean $\mathrm{pCO}_{2}$, and net sea-air $\mathrm{CO}_{2}$ flux over the global oceans. Deep-Sea Res. II, 56, 554-577, https:// doi.org/10.1016/j.dsr2.2008.12.009. 
Tamsitt, V., L. D. Talley, M. R. Mazloff, and I. Cerovečki, 2016: Zonal variations in the Southern Ocean heat budget. J. Climate, 29, 6563-6579, https://doi.org/10.1175/JCLI-D-15-0630.1.

Thomas, L. N., 2005: Destruction of potential vorticity by winds. J. Phys. Oceanogr., 35, 2457-2466, https://doi.org/10.1175/ JPO2830.1.

- , and R. Ferrari, 2008: Friction, frontogenesis, and the stratification of the surface mixed layer. J. Phys. Oceanogr., 38, 2501-2518, https://doi.org/10.1175/2008JPO3797.1.

— , J. R. Taylor, R. Ferrari, and T. M. Joyce, 2013: Symmetric instability in the Gulf Stream. Deep-Sea Res. II, 91, 96-110, https://doi.org/10.1016/j.dsr2.2013.02.025.

, - E. A. D'Asaro, C. M. Lee, J. M. Klymak, and A. Shcherbina, 2016: Symmetric instability, inertial oscillations, and turbulence at the Gulf Stream front. J. Phys. Oceanogr., 46, 197-217, https://doi.org/10.1175/JPO-D-15-0008.1.

Thompson, A. F., and M. K. Youngs, 2013: Surface exchange between the Weddell and Scotia Seas. Geophys. Res. Lett., 40, 5920-5925, https://doi.org/10.1002/2013GL058114.

__, and A. C. Naveira Garabato, 2014: Equilibration of the Antarctic Circumpolar Current by standing meanders. J. Phys. Oceanogr., 44, 1811-1828, https://doi.org/10.1175/ JPO-D-13-0163.1.

K. J. Heywood, S. E. Thorpe, A. H. H. Renner, and A. Trasviña, 2009: Surface circulation at the tip of the
Antarctic Peninsula from drifters. J. Phys. Oceanogr., 39, 3-26, https://doi.org/10.1175/2008JPO3995.1.

A. Lazar, C. Buckingham, A. C. N. Garabato, G. M. Damerell, and K. J. Heywood, 2016: Open-ocean submesoscale motions: A full seasonal cycle of mixed layer instabilities from gliders. J. Phys. Oceanogr., 46, 1285-1307, https://doi.org/10.1175/JPO-D-15-0170.1.

Todd, R. E., W. B. Owens, and D. L. Rudnick, 2016: Potential vorticity structure in the North Atlantic western boundary current from underwater glider observations. J. Phys. Oceanogr., 46, 327-348, https://doi.org/10.1175/JPO-D-15-0112.1.

Viglione, G. A., and A. F. Thompson, 2016: Lagrangian pathways of upwelling in the Southern Ocean. J. Geophys. Res. Oceans, 121, 6295-6309, https://doi.org/10.1002/ 2016JC011773.

Whitworth, T., W. D. Nowlin, A. H. Orsi, R. A. Locarnini, and S. G. Smith, 1994: Weddell Sea shelf water in the Bransfield Strait and Weddell-Scotia confluence. DeepSea Res. I, 41, 629-641, https://doi.org/10.1016/0967-0637 (94)90046-9.

A. H. Orsi, S. J. Kim, and W. D. Nowlin Jr., 1998: Water masses and mixing near the Antarctic Slope Front. Ocean, Ice, and Atmosphere: Interactions at the Antarctic Continental Margin, S. S. Jacobs and R. F. Weiss, Eds., Antarctic Research Series, Vol. 75, Amer. Geophys. Union, 1-27. 